\title{
Cyclic AMP Is a Hepatorenal Link Influencing Natriuresis and Contributing to Glucagon-induced Hyperfiltration in Rats
}

\author{
Mina Ahloulay, ${ }^{\star}$ Michèle Déchaux, ${ }^{\ddagger}$ Christine Hassler, ${ }^{\star}$ Nadine Bouby, ${ }^{\star}$ and Lise Bankir* \\ *INSERM Unité 90, Hôpital Necker-Enfants Malades, 75743 Paris Cedex 15, France; ${ }^{\ddagger}$ Laboratoire de Physiologie, \\ CHU Necker-Enfants Malades, 75743 Paris Cedex 15, France; and ${ }^{\S}$ Département de Biologie, Faculté des Sciences, Université Chouaïb \\ Doukkali, El Jadida, Maroc
}

\begin{abstract}
The effects of glucagon $(G)$ on proximal tubule reabsorption (PTR) and GFR seem to depend on a prior action of this hormone on the liver resulting in the liberation of a mediator and/or of a compound derived from amino acid metabolism. This study investigates in anesthetized rats the possible contribution of cAMP and urea, alone and in combination with a low dose of $G$, on phosphate excretion (known to depend mostly on PTR) and GFR. After a 60-min control period, cAMP $(5 \mathrm{nmol} / \mathrm{min} \times 100$ grams of body weight [BW]) or urea $(2.5 \mu \mathrm{mol} / \mathrm{min} \times 100$ grams $B W)$ was infused intravenously for $200 \mathrm{~min}$ with or without $\mathrm{G}(1.2 \mathrm{ng} / \mathrm{min} \times 100$ grams BW, a physiological dose which, alone, does not influence PTR or GFR). cAMP increased markedly the excretion of phosphate and sodium $(+303$ and $+221 \%$, respectively, $P<0.01$ for each) but did not alter GFR. Coinfusion of cAMP and $G$ induced the same tubular effects but also induced a $20 \%$ rise in GFR $(P<0.05)$. Infusion of urea, with or without $G$, did not induce significant effects on PTR or GFR. After G infusion at increasing doses, the increase in fractional excretion of phosphate was correlated with a simultaneous rise in plasma cAMP concentration and reached a maximum for doubling of plasma cAMP. These results suggest that CAMP, normally released by the liver into the blood under the action of $\mathrm{G},(a)$ is probably an essential hepatorenal link regulating the intensity of PTR, and (b) contributes, in conjunction with specific effects of $G$ on the nephron, to the regulation of GFR. (J. Clin. Invest. 1996. 98: 2251-2258.) Key words: liver • proximal tubule • phosphate • sodium • glomerular filtration rate
\end{abstract}

\section{Introduction}

Glucagon is a pancreatic hormone which stimulates several metabolic pathways in the liver, its first target organ. It plays an essential role in the maintenance of plasma glucose concen-

Part of this work was presented at the 27th Annual Meeting of the American Society of Nephrology, Orlando, FL, 1994 and published in abstract form (1994. J. Am. Soc. Nephrol. 5:599).

Address correspondence to Mina Ahloulay or Lise Bankir, INSERM U 90, Hôpital Necker-Enfants Malades, 75743 Paris Cedex 15, France. Phone: 33-1-44-49-52-43; FAX: 33-1-45-66-51-33; E-mail: bankir@citi2.fr

Received for publication 2 April 1996 and accepted in revised form 23 September 1996.

J. Clin. Invest.

(C) The American Society for Clinical Investigation, Inc.

0021-9738/96/11/2251/08 \$2.00

Volume 98, Number 10, November 1996, 2251-2258 tration by stimulating glycogenolysis and gluconeogenesis in situations of high energy needs or during fasting. On the other hand, and independent of the body's immediate needs in glucose, this hormone also plays a crucial role in disposal of nitrogen from the body. This is the case either after the ingestion of a large protein meal (or an amino acid infusion), when exogenous amino acids need to be metabolized and excess nitrogen excreted, or during periods of fast, when endogenous amino acids are used for gluconeogenesis. Actually, gluconeogenesis and ureagenesis are always linked (1), in order to ensure an appropriate disposal of the amine groups when the carbon chains of amino acids enter carbohydrate metabolism (2-4).

The kidney is also a target organ for glucagon, which influences solute transport in several nephron segments. As discussed in a previous paper (5), the tubular effects of glucagon on the distal segments of the nephron most probably result from a direct action of the hormone on specific receptors. This is the case for the stimulation of electrolyte reabsorption in the thick ascending limb of Henle. On the other hand, the effects of glucagon on the proximal tubule seem to be indirect and to require the previous action of glucagon on the liver (5).

In addition to its tubular effects, glucagon also influences renal hemodynamics. Several studies have established that this hormone participates in, or is even indispensable for, the postprandial increase in GFR (6-11). However, this effect of glucagon is probably indirect and involves other mediators (12) because the plasma concentration of glucagon required to increase GFR exceeds the usual peripheral concentration seen after a protein meal $(6,10,13)$. Moreover, direct infusion of glucagon into the renal artery fails to increase GFR in dogs $(10,14)$, humans (8), and rats (Ahloulay, M., personal observation). In previous experiments, we have confirmed that the rise in peripheral plasma glucagon concentration seen after a protein meal, and reproduced by glucagon infusion at a rate of $1.25 \mathrm{ng} /$ min $\times 100$ grams of body weight $(\mathrm{BW}),{ }^{1}$ failed to increase $\operatorname{GFR}(5,15)$. On the other hand, we observed that the rate of glucagon infusion necessary to increase GFR was only 3- to 10fold higher. This higher rate of infusion induced in peripheral blood a concentration of glucagon that is physiologic for the liver, given the normal porto-peripheral concentration gradient for pancreatic hormones, due to their direct release in the portal vein $(5,15)$. This is in good agreement with the study of Premen (16) showing that a glucagon infusion, which failed to increase GFR when infused peripherally, did increase GFR when infused in the portal vein. Taken together, these findings

1. Abbreviations used in this paper: $\mathrm{BW}$, body weight; $\mathrm{C}$, control periods; dDAVP, desamino D-arginine vasopressin; E, experimental periods; FE, fractional excretion; G1, glucagon infusion $1.25 \mathrm{ng} / \mathrm{min} \times$ 100 grams BW; G10, glucagon infusion $12.5 \mathrm{ng} / \mathrm{min} \times 100$ grams BW; $\mathrm{P}$, plasma. 
established that glucagon action on the kidney requires a prior action on the liver. It has been proposed that glucagon could induce the release from the liver of a vasoactive hormone, glomerulopressin, influencing the resistance of renal arterioles $(17,18$, and for reviews see references 19 and 20). Other studies have suggested that the link between the liver and the kidney could be a compound(s) derived from the metabolism of amino acids by the liver (21-23). The nature of this compound has not yet been determined.

The intracellular second messenger mediating the hepatic actions of glucagon is cAMP. Intravenous administration of glucagon is known to induce a marked and prompt rise in plasma cAMP, due to a rapid exit of this nucleotide from hepatocytes (24-28). cAMP is excreted by the kidney as a result of both filtration and secretion. It has been well established that cyclic nucleotides are secreted in the proximal tubule by a carrier-mediated process involving the organic acid transport system (29). On the other hand, a few studies suggest that cAMP secretion in the proximal tubule might be responsible for the effects of glucagon on the excretion of phosphate $(5,30)$. Plasma cAMP thus could represent a significant interorgan mediator linking the liver and the kidney. Could this nucleotide also be involved in the hemodynamic effects of glucagon on the kidney? Alternatively, or in conjunction, could urea, which is produced by the liver and excreted by the kidney under the influence of glucagon (15), represent another component of the hepatorenal link?

This study was undertaken to evaluate $(a)$ the influence of a rise in plasma cAMP or in plasma urea on renal function and (b) the possible contribution of cAMP and/or urea to glucagon-induced hyperfiltration. We hypothesized that rather than resulting from the influence of a single factor, the rise in GFR could depend on a combination of two or more factors acting jointly on the kidney.

Classical clearance experiments were conducted in normal, nonfasted rats in which a stable level of urinary concentrating activity was established to prevent uncontrolled changes in urinary flow rate and intrarenal urea recycling which could exert a confounding influence on GFR (5). Glucagon, cAMP, and urea were infused individually or in combination to evaluate the resulting changes in sodium, phosphate, urea, and water excretion, and in GFR.

\section{Methods}

\section{Animals and experimental protocols}

Adult male Wistar rats (Iffa-Credo, Lyon, France), 230-300 grams $\mathrm{BW}$, fed on a standard rat chow, were allowed food and water ad libitum until the time of the experiment. Clearance experiments were conducted in two series of anesthetized rats (Inactin, $10 \mathrm{mg} / 100$ grams BW, intraperitoneally; Research Biochemicals Inc., Natick, MA) with an experimental protocol identical to that described in our previous study (15). Surgery included tracheotomy and catheterization of one jugular vein, the two femoral arteries, and the bladder. Mean arterial blood pressure was monitored continuously through the right femoral artery (pressure processor; Gould Inc., Glen Burnie, MD). Isotonic saline $(\mathrm{NaCl} 0.9 \%)$ was infused intravenously during the entire experiment at a rate of $15 \mu \mathrm{l} / \mathrm{min} \times 100$ grams BW. After completion of the surgery and for the rest of the experiment, Inutest (Laevosan Gesellschaft, Linz, Germany) was infused at $0.75 \mathrm{mg} / \mathrm{min} \times 100$ grams $\mathrm{BW}$. To ensure a relatively stable urinary concentrating activity (5), desamino D-arginine vasopressin (dDAVP; Minirin, Ferring, Malmö, Sweden), an antidiuretic analogue of vasopressin, was infused at 1.66 $\mathrm{pg} / \mathrm{min} \times 100$ grams BW. As shown in a previous study, this improves the stability of basal renal function and prevents the possible confounding influence of uncontrolled changes in urinary flow rate on solute excretion and renal hemodynamics (5).

Protocol 1 . After surgery and $1 \mathrm{~h}$ of equilibration $(\mathrm{t}=0)$, urine was collected in preweighed tubes for four 20-min control periods (C) after which the experimental infusion was started and urine was collected for six 20 -min experimental periods $(\mathrm{E})$. Blood samples $(\approx 300$ $\mu \mathrm{l})$ were taken from the left femoral artery at the beginning and end of the equilibration period, and then every 40 min during the next 200 min (that is at the beginning of periods $1,3,5,7,9$, and at the end of period 10). Plasma concentrations at the midpoint of each clearance period were interpolated from the values measured in these samples.

This series of experiments included seven groups of rats, one of which served as time control. In the other six groups, urea, cAMP (Sigma, St. Louis, MO), or glucagon (highly purified porcine glucagon; Novo Industry, Bagsvaerd, Denmark) were infused alone or in combination. The different experimental infusions and the corresponding abbreviations are shown in Table I (Table I also shows two groups of rats studied previously that received a glucagon infusion at two different rates, reproducing physiologic concentrations for either the kidney [G1] or the liver [G10]; see explanations in reference 5). Urea was infused at a rate close to that used in our previous study (15). Regarding cAMP, this nucleotide has rarely been infused in vivo. We chose to infuse $5 \mathrm{nmol} / \mathrm{min} \times 100$ grams $\mathrm{BW}$, a rate 17 -fold lower than that used by Lorentz (31), and comparable to that used in other studies $(30,32,33)$. The glucagon infusion rate used in the present study (G1) was $1.2 \mathrm{ng} / \mathrm{min} \times 100$ grams $\mathrm{BW}$, corresponding to the lowest infusion rate of our previous study (a rate which does not increase GFR).

Protocol 2. In our previous experiments, changes in plasma cAMP in response to glucagon infusions G1 or G10 had been measured in a few rats (5). To extend these observations, an additional series of rats was used to determine the concentrations of cAMP in peripheral blood and urine in different conditions, and the associated changes in GFR and phosphate excretion. Inutest and dDAVP were infused as in protocol 1, and the experiments included one $\mathrm{C}$ and one $\mathrm{E}$ period. During each period, urine was collected for $60 \mathrm{~min}$ (after an equilibration period of $60 \mathrm{~min}$ for $\mathrm{C}$, or $40 \mathrm{~min}$ for $\mathrm{E}$ ). During $\mathrm{E}$, different rats received the following infusions. Three rats received glucagon at a rate of $120 \mathrm{ng} / \mathrm{min} \times 100$ grams BW (a rate 100 -fold higher than in protocol 1), two rats received cAMP at a rate similar to that in protocol 1, and one rat served as control (no change during E).

\section{Analysis, calculations, and statistics}

Urinary flow rate was evaluated by gravimetry. Osmolality was measured with a freezing point osmometer (Roebling, Berlin, Germany).

Table I. Experimental Infusions Given in the Different Groups (per 100 grams BW)

\begin{tabular}{lcccc}
\hline \multicolumn{1}{c}{ Groups } & $n$ & Glucagon & cAMP & Urea \\
\hline & & $n g /$ min & $n m o l / m i n$ & $\mu m o l / m i n$ \\
Control & 8 & 0 & 0 & 0 \\
G1* & 8 & 1.2 & 0 & 0 \\
G10* & 7 & 12 & 0 & 0 \\
cAMP & 4 & 0 & 5.0 & 0 \\
Urea & 8 & 0 & 0 & 2.5 \\
cAMP + urea & 4 & 0 & 5.0 & 2.5 \\
G1 + urea & 4 & 1.2 & 0 & 2.5 \\
G1 + cAMP & 7 & 1.2 & 5.0 & 0 \\
G1 + cAMP + urea & 5 & 1.2 & 5.0 & 2.5 \\
& & & & \\
\hline
\end{tabular}

$n$, number of rats per group; *data from preceding study (5). 
Table II. GFR ( $\mathrm{ml} / \mathrm{min})$ Measured during $C$ and E Periods in the Different Rat Groups

\begin{tabular}{lccc}
\hline \multicolumn{1}{c}{ Groups } & $\mathrm{C}$ & $\mathrm{E}$ & $\Delta=(\mathrm{E}-\mathrm{C})$ \\
\hline Control & $3.05 \pm 0.31$ & $2.99 \pm 0.29$ & $-0.06 \pm 0.13$ \\
G1 & $2.70 \pm 0.13$ & $2.53 \pm 0.12$ & $-0.20 \pm 0.10$ \\
G10* & $2.57 \pm 0.13$ & $3.13 \pm 0.23$ & $+0.57 \pm 0.13^{\ddagger}$ \\
& & & \\
cAMP & $2.35 \pm 0.18$ & $2.45 \pm 0.14$ & $+0.10 \pm 0.11$ \\
Urea & $2.60 \pm 0.15$ & $2.71 \pm 0.17$ & $+0.11 \pm 0.11$ \\
cAMP + urea & $3.08 \pm 0.28$ & $3.18 \pm 0.46$ & $+0.10 \pm 0.30$ \\
G1 + urea & $2.38 \pm 0.19$ & $2.23 \pm 0.09$ & $-0.15 \pm 0.12$ \\
G1 + cAMP & $2.32 \pm 0.11$ & $2.76 \pm 0.24$ & $+0.44 \pm 0.18^{\S}$ \\
G1 + cAMP + urea & $2.94 \pm 0.25$ & $3.54 \pm 0.36$ & $+0.60 \pm 0.14^{\S}$
\end{tabular}

Paired $t$ test between E and C: ${ }^{\S} P<0.05 ;{ }^{\ddagger} P<0.01$. *Data taken from a previous study (5).

Inutest concentration in plasma and urine was measured by the anthrone method (34). Inutest clearance was considered to represent GFR. The concentration of urea in plasma and urine was measured by a modification of the Berthelot method (Urea-Kit Biomérieux, Lyon, France) and that of phosphate by standard methods (RA 1000; Technicon Instruments Corp., Tarrytown, NY). cAMP was measured in plasma by radioimmunoassay after acetylation, using a commercial kit (RIA ${ }^{3} \mathrm{H}$ cAMP; Amersham Corp., Arlington Heights, IL).

In protocol 1, the results obtained for each rat during the four control (1-4) and the last four experimental periods (7-10) were averaged to provide one $\mathrm{C}$ and one $\mathrm{E}$ value per rat. Means $\pm \mathrm{SE}$ for $\mathrm{C}$ and $\mathrm{E}$ were then calculated for each group. In protocols 1 and 2, the statistical significance of the differences observed between $\mathrm{C}$ and $\mathrm{E}$ in each group was evaluated by paired $t$ test. In addition, the changes in GFR observed in the different groups in protocol 1 were compared by one-way ANOVA followed by the Fisher post-hoc test.

\section{Results}

The infusion of dDAVP in all rats during the experiments ensured a similar urine flow rate and osmolality in all groups (range 7.0-10.0 $\mu \mathrm{l} / \mathrm{min}$ and 1,670-1,995 mosmol $/ \mathrm{kg} \mathrm{H}_{2} \mathrm{O}$, respectively). No significant changes between control and experimental periods were observed in the time-control group except for a $36 \%$ increase in phosphate excretion $(P<0.01)$.

GFR. Table II and Fig. 1 show the results concerning GFR for the groups explored in protocol 1. Results obtained in a previous study for glucagon infusion at rates of 1.25 and 12.5 $\mathrm{ng} / \mathrm{min} \times 100$ grams BW (G1 and G10, respectively) are also shown as a reference. $\mathrm{G} 1$, which reproduced a physiological concentration of glucagon in peripheral blood, failed to increase GFR, whereas a 10-fold higher infusion rate increased GFR by $21.5 \%$ (5). Urea alone or combined with cAMP or G1 was without effect. cAMP alone did not alter GFR, whereas cAMP + G1 increased GFR significantly $(+18.5 \%)$. Coinfusion of urea with cAMP and G1 enhanced GFR somewhat further $(+20.0 \%)$ (Fig. 1). When changes in GFR in the different experimental groups were analyzed by ANOVA, the only changes which differed significantly from those in the control group were found in G10, cAMP + G1, and cAMP + G1 + urea $(P<0.01, P<0.05$ and $P<0.01$, respectively). Moreover, G1 combined with cAMP induced a significantly different effect than $\mathrm{G} 1$ alone $(P<0.01)$.

Water and electrolytes. Fig. 2 depicts the influence of cAMP and glucagon (G10) on solute and water excretion. cAMP infusion increased urinary flow rate and excretion of the main urinary solutes. However, the magnitude of these changes was not uniform. Sodium and phosphate excretion was markedly increased $(>200 \%)$, whereas excretion of water, potassium, and urea was increased more modestly $(\approx 20-50 \%)$. (This effect was also observed in rats which did not receive dDAVP [34a].) These increased excretions were probably responsible for a decline in plasma concentration of urea $(-7.5 \%)$ and phosphate $(-14.0 \%)$, a decline which did not reach statistical significance, however. These changes induced by cAMP infusion are very similar to those observed after G10 infusion regarding both water and solute excretions (Fig. 2) and plasma composition (5).

Fig. 3 illustrates the influence of the different experimental infusions on fractional excretion of phosphate $\left(\mathrm{FE}_{\mathrm{PO}_{4}^{-}}\right)$. As al-

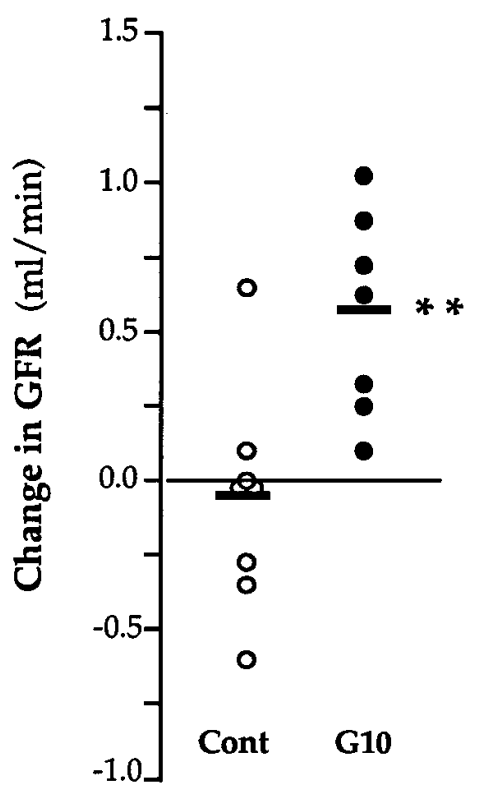

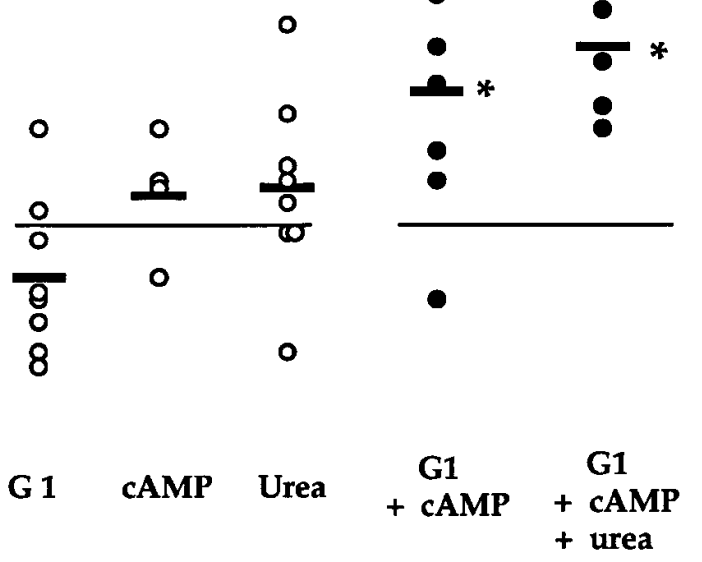

Figure 1. Changes in GFR observed between $\mathrm{E}$ and $\mathrm{C}$ periods in response to the different infusions. Each point represents a single rat. Group means are shown by horizontal bars. Results of glucagon experiments G10 and G1 were obtained in a previous study (5). Paired $t$ test (E vs. C): $* P<0.05 ; * * P<0.01$. 


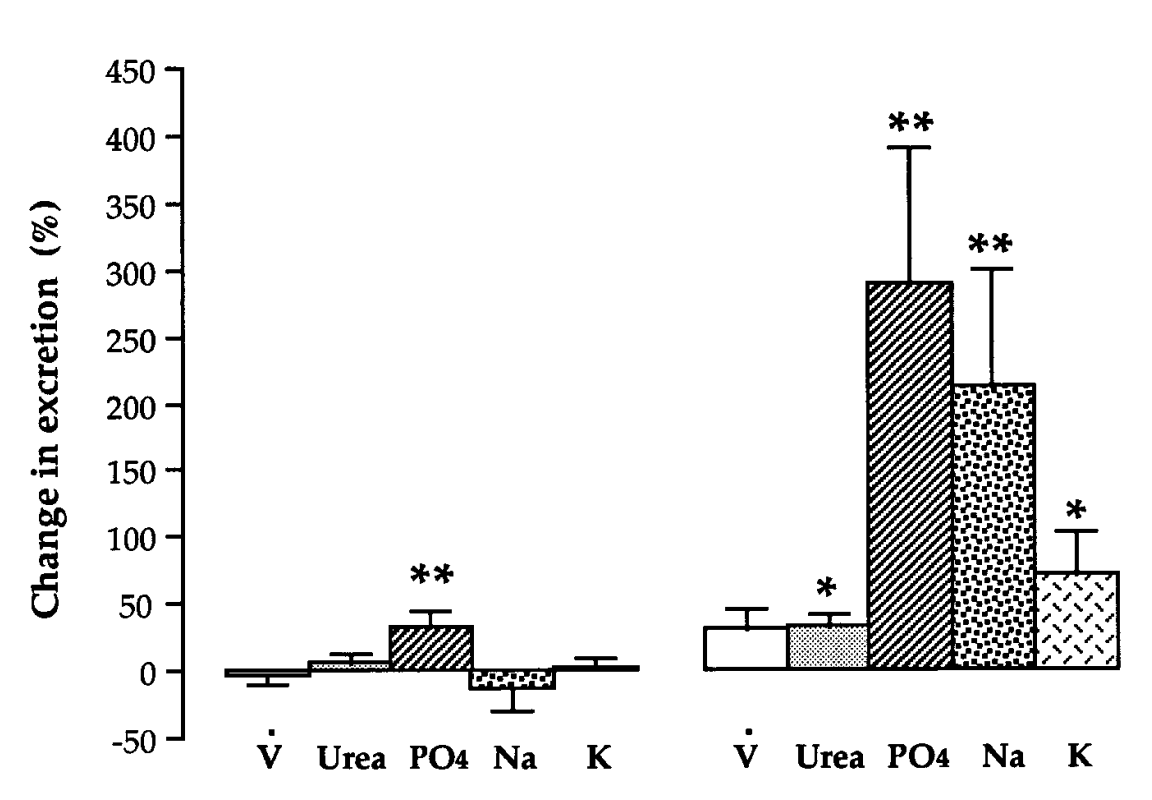

Control

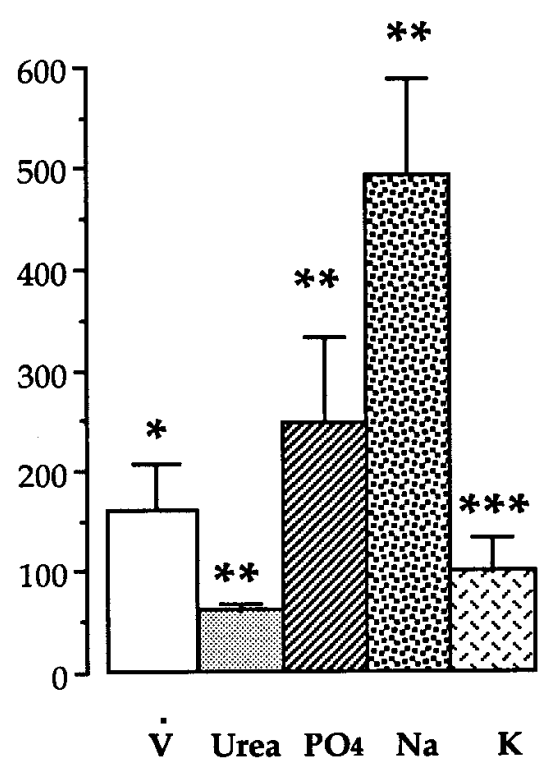

Glucagon 10

Figure 2. Changes in excretion of water $(V)$, urea, phosphates, sodium, and potassium in the time-control group $(n=4)$ and in the groups receiving cAMP $(n=4)$ or glucagon (G10) infusion $(n=7)$. Paired $t$ test (E vs. C): $* P<0.05 ; * * P<0.01 ; * * P<0.001$. Urinary flow rate and absolute excretion of urea, phosphates, sodium, and potassium during the control period were $7.71 \pm 0.56 \mu 1 / \mathrm{min}$, and $5.67 \pm 0.47,0.460 \pm 0.074$, $0.257 \pm 0.038$, and $2.12 \pm 0.31 \mu \mathrm{mol} / \mathrm{min}$, respectively (means $\pm \mathrm{SE}$ of all rats). Results of glucagon experiments G10 were obtained in a previous study (5).

ready described, glucagon increases $\mathrm{FE}_{\mathrm{PO}_{4}^{-}}$in a dose-dependent fashion (absolute change: $+5.5 \pm 1.6$ and $+12.3 \pm 2.5 \%$ of filtered load, for G1 and G10, respectively) (5). In all groups receiving $\mathrm{CAMP}$, whether alone or in combination with urea and/or G1, a large and comparable increase in $\mathrm{FE}_{\mathrm{PO}_{4}^{-}}$was observed $(\approx 14 \%)$. Urea infusion induced a significant rise in $\mathrm{FE}_{\mathrm{PO}_{-}^{-}}(+8.8 \pm 2.3 \%)$ which was even greater when $\mathrm{G} 1$ was coinfused with urea $(+11.8 \pm 1.0 \%)$.

Protocol 2 explored the relationship between changes in plasma cAMP $\left(\mathrm{P}_{\mathrm{cAMP}}\right)$ and changes in GFR and in phosphate reabsorption induced by either glucagon or cAMP infusion. As observed in Fig. 4, for the seven rats in which the changes in $\mathrm{P}_{\text {cAMP }}$ were moderate $(<40 \mathrm{nM}$, i.e., a doubling of the basal value), a highly significant correlation was observed between changes in $\mathrm{FE}_{\mathrm{PO}_{-}^{-}}$and the simultaneous changes in $\mathrm{P}_{\text {cAMP }}(r=$ 0.995, $P<0.001)$. For the five other rats in which higher changes in $\mathrm{P}_{\text {cAMP }}$ occurred, $\mathrm{FE}_{\mathrm{PO}_{4}^{-}}$reached a plateau probably corresponding to the maximal inhibition of phosphate reabsorption. Concerning GFR, the changes in the first seven rats also tended to be correlated with the simultaneous changes in $\mathrm{P}_{\text {cAMP }}(r=0.680,0.10>P>0.05)$. Larger changes in $\mathrm{P}_{\text {cAMP }}$ $(<200 \mathrm{nM})$ were associated with maximal changes in GFR when they resulted from a high rate of glucagon infusion. In contrast, they were not accompanied by any change in GFR when they resulted from cAMP infusion, as already observed in protocol 1 (Fig. 2).

Urea. As described earlier, the infusion of glucagon at a rate of $12.5 \mathrm{ng} / \mathrm{min} \times 100$ grams $\mathrm{BW}(\mathrm{G} 10)$ stimulates urea

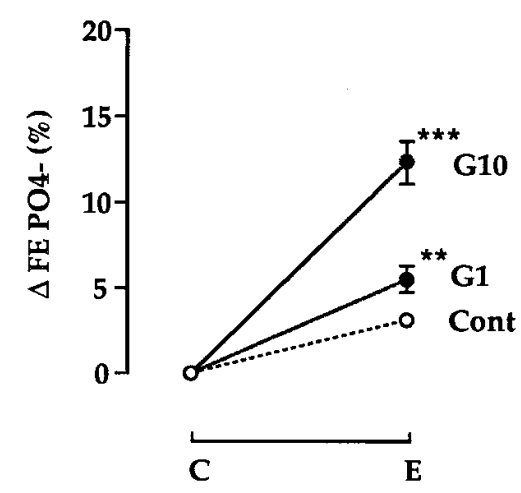

Figure 3. Influence of the different infusions on fractional phosphate excretion between $\mathrm{C}$ and $\mathrm{E}$ periods. The ordinate shows the absolute changes $(\Delta=\mathrm{E}-\mathrm{C})$ in FE expressed as a percentage of the filtered load. Results of glucagon experiments G1 and G10 were obtained in a previous study (5). $c A$, cAMP; $U$, urea. Basal $\mathrm{FE}_{\mathrm{PO}-}$ was $6.04 \pm 0.70 \%$ (mean \pm SE of all rats). For number of rats in each group, see Table I (in control group, $n=4$ only for phosphate measurements). Paired $t$ test (E vs. C): $* P<0.05$; $* * P<0.01 ; * * * P<0.001$.

2254 Ahloulay etal. 

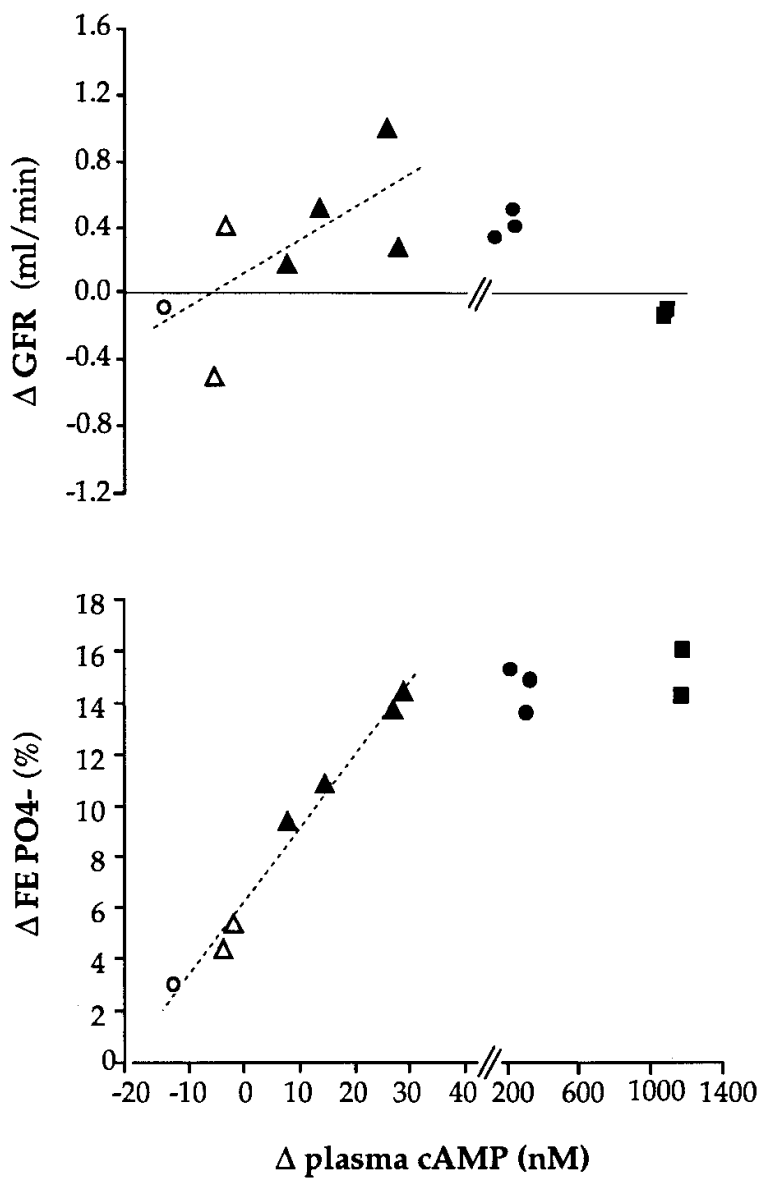

Figure 4. Relationship between changes in GFR or in fractional phosphate excretion and changes in plasma cAMP concentration induced by the infusion of glucagon or cAMP. Results of glucagon experiments G1 and G10 were obtained in a previous study (5). Basal GFR, $\mathrm{FE}_{\mathrm{PO}_{4}^{-}}$andP cAMP were $2.62 \pm 0.11 \mathrm{ml} / \mathrm{min}, 5.98 \pm 0.73 \%$, and $49 \pm 7 \mathrm{nmol} /$ liter, respectively (mean $\pm \mathrm{SE}$ of the $12 \mathrm{rats}$ ). Open circles, time control rat; open triangles, G1; closed triangles, G10; closed circles, G100; closed squares, cAMP.

synthesis in the liver and increases the fractional excretion of urea $\left(\mathrm{FE}_{\text {urea }}\right)$ in the kidney (percent change, $+52.3 \pm 12.8 \%$, $P<0.001)(5,15)$. This simultaneous effect on the two organs is accompanied by a small but significant decrease in plasma urea $\left(\mathrm{P}_{\text {urea }}\right)$ (Table III), indicating that the stimulation of urea excretion exceeds that of urea synthesis. In contrast, when exogenous urea was infused, $\mathrm{P}_{\text {urea }}$ increased significantly (Table III), indicating that the rise in urea excretion did not match the rate of urea infusion $(\approx 7 \mu \mathrm{mol} / \mathrm{min}$ for a 280 -gram rat $)$. Actually, $\mathrm{FE}_{\text {urea }}$ rose much less in this case $(+18.5 \pm 8.1 \%$, NS) than after glucagon infusion (see above). cAMP infusion increased urea absolute excretion and FE significantly (percent change in $\mathrm{FE},+38.1 \pm 13.1 \%, P<0.05)$, and tended to decrease $\mathrm{P}_{\text {urea }}$ (Table III). When G1, cAMP, and urea were coinfused, the rise in urea excretion was comparable with that seen with G10. However, it remained lower than the infusion rate of exogenous urea, and $\mathrm{P}_{\text {urea }}$ rose significantly (Table III).

\section{Discussion}

This study brings new information regarding the humoral control of renal function. First, it confirms that plasma cAMP exerts an influence on proximal reabsorption. Second, it suggests that the proximal effects of glucagon are likely dependent on the release in peripheral blood of liver-borne cAMP and on the subsequent uptake of this nucleotide by proximal cells. Third, it suggests that the glucagon-induced increase in GFR depends on the combination of a physiological rise in peripheral plasma glucagon concentration and of a simultaneous rise in plasma cAMP resulting from glucagon action on the liver.

Influence of plasma cAMP on renal function. It is usually believed that circulating cAMP does not influence cellular functions throughout the body because most cells are impermeable to this nucleotide (35). This explains why few studies have investigated the effects of cAMP infusion on kidney function (30-33). However, in some cells, cAMP is transported by the organic acid transport system inhibitable by probenecid and para-aminohippuric acid $(29,36-38)$. This system is present in hepatocytes and in cells of the proximal tubule, mostly in the pars recta $(39,40)$. As a result, cAMP generated in hepatocytes may be secreted in the blood (24-27) and taken up and secreted by proximal tubule cells $(29,36,41)$.

The present results show that cAMP influences the excretion of the four major solutes with a predominant effect on sodium and phosphate. Because pars recta cells take up cAMP, cAMP infusion should increase their intracellular cAMP con-

Table III. Plasma Urea and Urea Excretion in the Different Groups

\begin{tabular}{|c|c|c|c|c|c|c|}
\hline \multirow[b]{2}{*}{ Groups } & \multicolumn{3}{|c|}{ Plasma urea $(\mathrm{mM})$} & \multicolumn{3}{|c|}{ Urea excretion $(\mu \mathrm{mol} / \mathrm{min})$} \\
\hline & $\mathrm{C}$ & $\mathrm{E}$ & $\Delta=\mathrm{E}-\mathrm{C}$ & $\mathrm{C}$ & $\mathrm{E}$ & $\Delta=\mathrm{E}-\mathrm{C}$ \\
\hline Control & $7.1 \pm 0.4$ & $6.8 \pm 0.4$ & $-0.4 \pm 0.2$ & $6.2 \pm 0.8$ & $7.1 \pm 0.9$ & $+0.8 \pm 0.4$ \\
\hline $\mathrm{G} 1 *$ & $7.6 \pm 0.8$ & $7.1 \pm 0.7$ & $-0.5 \pm 0.3$ & $6.8 \pm 0.6$ & $6.9 \pm 0.7$ & $+0.1 \pm 0.4$ \\
\hline G10* & $6.5 \pm 0.6$ & $5.8 \pm 0.5$ & $-0.8 \pm 0.3^{\ddagger}$ & $6.7 \pm 0.8$ & $10.5 \pm 1.3$ & $+3.8 \pm 0.6^{\S}$ \\
\hline cAMP & $5.5 \pm 0.5$ & $5.1 \pm 0.3$ & $-0.5 \pm 0.2$ & $4.5 \pm 0.3$ & $6.0 \pm 0.1$ & $+1.4 \pm 0.4$ \\
\hline Urea & $7.4 \pm 0.4$ & $8.9 \pm 0.6$ & $+1.5 \pm 0.3^{\ddagger}$ & $6.8 \pm 0.8$ & $9.6 \pm 0.7$ & $+2.8 \pm 0.8 \|$ \\
\hline cAMP + urea & $7.4 \pm 0.8$ & $9.5 \pm 1.2$ & $+2.1 \pm 0.5^{\ddagger}$ & $6.8 \pm 0.9$ & $9.9 \pm 1.1$ & $+3.1 \pm 0.3^{\|}$ \\
\hline $\mathrm{G} 1$ + urea & $6.6 \pm 0.5$ & $7.9 \pm 0.5$ & $+1.3 \pm 0.2^{\ddagger}$ & $7.0 \pm 0.8$ & $8.9 \pm 0.4$ & $+1.9 \pm 0.4$ \\
\hline $\mathrm{G} 1+\mathrm{cAMP}$ & $6.2 \pm 0.4$ & $5.6 \pm 0.4$ & $-0.6 \pm 0.2^{\ddagger}$ & $6.0 \pm 0.6$ & $7.1 \pm 0.9$ & $+1.0 \pm 0.5$ \\
\hline $\mathrm{G} 1+\mathrm{cAMP}+$ urea & $6.8 \pm 0.4$ & $8.3 \pm 0.8$ & $+1.5 \pm 0.4^{\ddagger}$ & $7.0 \pm 0.7$ & $11.2 \pm 0.9$ & $+4.1 \pm 0.6$ \\
\hline
\end{tabular}

Paired $t$ test between E and C: ${ }^{\ddagger} P<0.05 ;{ }^{\|} P<0.01 ;{ }^{\S} P<0.001$. ${ }^{*}$ Data taken from a previous study (5). 
centration, thus inhibiting sodium phosphate and sodium bicarbonate cotransport, as cAMP generated intracellularly under the influence of PTH would do (42). Phosphate resulting from the breakdown of cAMP by phosphodiesterases probably also contributes to the rise in phosphate excretion $(33,43)$.

The fact that intravenously infused cAMP reduces late proximal reabsorption suggests that the plasma level of cAMP may permanently influence the intensity of late proximal tubule function. This influence is probably physiologically significant because small increments in $\mathrm{P}_{\text {cAMP }}$ are accompanied by detectable changes in $\mathrm{FE}_{\mathrm{PO}_{4}^{-}}$, and maximum response occurs for only doubling basal $\mathrm{P}_{\text {cAMP }}$ (Fig. 4). Accordingly, cAMP might be an interorgan link between organs releasing cAMP in the blood (mainly the liver [24-27] and the heart [44]) and the kidney.

Interestingly, in the years after the discovery of the role of cAMP as a second messenger, a number of reports have emphasized that glucagon stimulates hepatic cAMP production and release in blood (or perfusate) $\sim 40$-fold more than epinephrine, although they induce quantitatively similar metabolic effects $(24,25,45,46)$. Our results suggest that the extra amounts of cAMP produced by the liver in response to glucagon probably serve as an extracellular messenger acting on the kidney.

Role of hepatic cAMP in the glucagon-induced changes in proximal reabsorption and in GFR. Several previous studies have shown that glucagon exerts natriuretic and phosphaturic effects $(5,47-51)$ by reducing the reabsorption of sodium, phosphate, and water in the whole proximal tubule, with a predominant influence in the pars recta (52). However, no glucagon receptors (53) and no glucagon-sensitive adenylate cyclase activity (54) have been found in this nephron segment. The present results strongly suggest that the effects of glucagon on the proximal tubule are dependent on the uptake of hepatic cAMP by proximal tubule cells. However, the intensity of the cAMP-dependent reduction in pars recta reabsorption can be expected to vary with the glucagon/insulin concentration ratio in portal blood, and not with the absolute glucagon concentration observed in peripheral blood, because insulin decreases the glucagon-induced release of cAMP by the liver (55-57).

Several studies (including two from our laboratory) have shown that intravenous infusion of glucagon that induces increments in peripheral plasma glucagon within the physiological range does not increase $\operatorname{GFR}(5,6,10,13,15)$. In contrast, glucagon infusion increasing plasma concentration to $900 \mathrm{pg} /$ $\mathrm{ml}$ or above (5) (a concentration usually achieved in the portal circulation) or infusion of lower amounts in the portal vein (10) does increase GFR. It has been proposed that the rise in GFR could depend on the liberation by the liver of a mediator or metabolite derived from amino acid metabolism $(6,15,16$, 21). A putative liver-derived vasoactive mediator glomerulopressin has not been well characterized to date (for review see reference 20). In this study, we evaluated whether two metabolites, cAMP and urea, released by the liver under the action of glucagon, could mediate the liver-dependent effects of glucagon on the kidney. Our results show that cAMP plays a crucial role but that the contribution of urea is only modest.

Although an infusion of cAMP is able to mimic the proximal effects of glucagon, it does not exert an influence on GFR. However, when cAMP and glucagon (G1) are combined, a distinct increase in GFR occurs. Actually, this combination reproduces for the kidney the conditions met physiologically when glucagon is normally released by the pancreas in the hepatic circulation. Accordingly, the present study shows that in normal conditions the combination of two factors acting simultaneously on the kidney is required for influencing GFR, namely the renal action of liver-derived cAMP and the direct renal action of glucagon. That cAMP is necessary but not sufficient to raise GFR is also suggested by the absence of any change in GFR when large increases in $\mathrm{P}_{\text {cAMP }}$ Occur without glucagon addition, contrasting with the parallel changes observed in $\mathrm{P}_{\text {cAMP }}$ and in GFR after G1 or G10 infusions (Fig. 4). Note that the release of variable amounts of adenosine in the nephron lumen, due to the breakdown of cAMP, may partially counteract the increase in GFR, thus weakening the correlation shown in Fig. 4, because luminal adenosine has been shown to reduce GFR (58).

Because a high infusion rate of glucagon (G10) increases simultaneously urea synthesis by the liver and GFR (15), it was interesting to consider whether increased urea delivery to the kidney could play a role in the renal hemodynamic response to this hormone. Urea alone did not influence GFR (Table II). However, it seemed to have a modest additive effect above that due to the combination of G1 and cAMP. Notably, the increased excretion of urea in groups receiving an urea infusion occurred without any change in GFR and was solely due to a rise in $\mathrm{P}_{\text {urea }}$. In contrast, the similar increase in urea excretion seen after glucagon infusion (G10) resulted from a rise in GFR without any change in $\mathrm{P}_{\text {urea }}$, as already underlined $(5,15)$.

The contribution of glucagon to the rise in GFR seen after a protein meal or an amino acid infusion remains controversial $(6-11,13,59)$. This might be due to the fact that the rise in GFR is also partly dependent on the release of hepatic cAMP, which itself depends on the balance between insulin and glucagon, not on glucagon alone.

How can the combination of cAMP and glucagon induce a rise in GFR? Glucagon (G1 level) is known to stimulate directly $\mathrm{NaCl}$ reabsorption in the thick ascending limb $(60,61)$. This could decrease $\mathrm{NaCl}$ concentration at the macula densa. On the other hand, glucagon (G10 or above) has been shown to depress tubulo-glomerular feedback (62). Because glucagon (G1) alone does not increase GFR, it is likely that this effect at the macula densa level becomes significant only when a prior cAMP-dependent reduction in late proximal reabsorption provides a higher fluid and solute delivery to the loop. This hypothesis is compatible with the observations that inhibition of reabsorption in either the proximal tubule (63) or the loop of Henle (64) prevents the protein-induced rise in GFR.

In this study, the intravenous cAMP infusion resulted in a plasma concentration which is much higher than that induced by glucagon administration (Fig. 4). Thus, further studies using lower infusion rates of cAMP are necessary to confirm the proposed influence of circulating cAMP on renal function. Alternatively, attempts to prevent cAMP secretion in the proximal tubule during glucagon administration (G10) should bring even more convincing evidence on this role. In preliminary experiments, we observed that infusion of para-aminohippuric acid (which competes with cAMP for secretion by the proximal tubule) prevents the rise in GFR induced by glucagon G10 infusion (Ahloulay, M., F. Machet, and L. Bankir, unpublished results).

Possible involvement of plasma cAMP in several pathophysiologic conditions. The fact that plasma cAMP could influence proximal reabsorption and contribute to glucagon- 
induced hyperfiltration provides pertinent explanations for several clinical disorders. Impaired cAMP production by the diseased liver could explain the sodium and water retention of cirrhosis, and abnormally low cAMP production due to hyperinsulinemia could account for the antinatriuretic effect of insulin (65) and for the edema of Kwashiorkor (malnutrition characterized by intake of food with high carbohydrate and low protein content [66]). Conversely, the natriuresis of fasting (67) could be due to an increased cAMP production under the influence of increased glucagon secretion.

That both glucagon and cAMP are required to increase GFR can account for the fact that a rate of glucagon infusion which increases GFR in normal dogs (48) fails to do so in cirrhotic dogs (68) in which the hepatic cAMP response to glucagon is blunted. The progressive oliguric renal failure characteristic of the hepatorenal syndrome might be due to a sustained defect in hepatic cAMP production. On the other hand, the hyperfiltration of diabetes mellitus could be due, at least in part, to the combination of elevated glucagon secretion (69, 70) and exaggerated cAMP release by the liver in the absence of insulin action (71). It is noteworthy that immunoneutralization of circulating glucagon induced a significant fall in GFR in rats with streptozotocin-induced diabetes mellitus (72).

In conclusion, this study brings a new insight into the nature of the hepatorenal link suspected in several physiologic and pathologic conditions and the mechanism by which glucagon influences renal hemodynamics. The present results suggest that liver-borne cAMP exerts a permanent influence on the intensity of proximal function and that glucagon and circulating cAMP must act simultaneously on the kidney to increase GFR after a protein meal. Alterations in cAMP production by the liver in either direction and/or marked changes in glucagon and insulin secretion could explain disorders in GFR and in sodium and water excretion observed in various pathologic conditions.

\section{Acknowledgments}

We thank Dr. Rékia Belahsen (Université Chouaïb Doukkali, El Jadida, Maroc) for her contribution to this study and Doreen Broneer for reviewing the English.

This work was supported, in part, by the Groupe Danone (Paris, France). M. Ahloulay received a scholarship from the Fondation pour la Recherche Médicale.

\section{References}

1. Meijer, A.J., W.H. Lamers, and R.A.F.M. Chamuleau. 1990. Nitrogen metabolism and ornithine cycle function. Physiol. Rev. 70:701-748.

2. Holst, J.J. 1983. Glucagon: how to prove its role in amino acid metabolism. Eur. J. Clin. Invest. 13:107-108.

3. Boden, G., L. Tappy, F. Jadali, R.D. Hoeldtke, I. Rezvani, and O.E. Owen. 1990. Role of glucagon in disposal of an amino acid load. Am. J. Physiol. 259(Endocrinol. Metab. 22):E225-E232.

4. Bankir, L. 1996. Urea and the kidney. In The Kidney. B.M. Brenner, editor. W.B. Saunders Co., Philadelphia. 571-606.

5. Ahloulay, M., M. Déchaux, K. Laborde, and L. Bankir. 1995. Influence of glucagon on GFR and on urea and electrolyte excretion: direct and indirect effects. Am. J. Physiol. 269(Renal Fluid Electrolyte Physiol. 38):F225-F235.

6. Castellino, P., C. Giordano, A. Perna, and R.A. DeFronzo. 1988. Effects of plasma amino acid and hormone levels on renal hemodynamics in humans. Am. J. Physiol. 255(Renal Fluid Electrolyte Physiol. 24):F444-F449.

7. DeSanto, N.G., S. Coppola, P. Anastasio, G. Coscarella, G. Capasso, P. Castellino, R. DeMercato, L. Bellini, P. Strazzullo, P. Guadagno, and C. Pignatelli. 1990. Pancreatectomy abolishes the renal hemodynamic response to a meat meal in man. Nephron. 55:85-86.

8. Friedlander, G., F. Blanchet-Benqué, A. Nitenberg, C. Laborie, R. As- san, and C. Amiel. 1990. Glucagon secretion is essential for amino acid-induced hyperfiltration in man. Nephrol. Dial. Transplant. 5:110-117.

9. Giordano, M., P. Castellino, E.L. McConnell, and R.A. DeFronzo. 1994 Effect of amino acid infusion on renal hemodynamics in humans: a doseresponse study. Am. J. Physiol. 267(Renal Fluid Electrolyte Physiol. 36):F703F708.

10. Premen, A.J., J.E. Hall, and L.J. Smith. 1985. Postprandial regulation of renal hemodynamics: role of pancreatic glucagon. Am. J. Physiol. 248(Renal Fluid Electrolyte Physiol. 17):F656-F662.

11. Wada, L., B.R. Don, and M. Schambelan. 1991. Hormonal mediators of amino acid-induced glomerular hyperfiltration in humans. Am. J. Physiol. 260(Renal Fluid Electrolyte Physiol. 29):F787-F792.

12. Tolins, J.P. 1992. Mechanisms of glucagon-induced renal vasodilation: role of prostaglandins and endothelium-derived relaxing factor. J. Lab. Clin. Med. 120:941-948.

13. Bergström, J., M. Ahlberg, and A. Alvestrand. 1985. Influence of protein intake on renal hemodynamics and plasma hormone concentrations in normal subjects. Acta Med. Scand. 217:189-196.

14. Briffeuil, P., T.H. Thu, and J. Kolanowski. 1996. A lack of a direct action of glucagon on kidney metabolism, hemodynamics, and renal sodium handling in the dog. Metab. Clin. Exp. 45:383-388.

15. Ahloulay, M., N. Bouby, F. Machet, M. Kubrusly, C. Coutaud, and L. Bankir. 1992. Effects of glucagon on glomerular filtration rate and urea and water excretion. Am. J. Physiol. 263(Renal Fluid Electrolyte Physiol. 32):F24-F36.

16. Premen, A.J. 1987. Splanchnic and renal hemodynamic responses to intraportal infusion of glucagon. Am. J. Physiol. 253(Renal Fluid Electrolyte Physiol. 22):F1105-F1112.

17. Uranga, J., R. Fuenzalida, A.L. Rapoport, and E. DelCastillo. 1979. Effect of glucagon and glomerulopressin on the renal function of the dog. Horm. Metab. Res. 11:275-279.

18. Alvestrand, A., and J. Bergström. 1984. Glomerular hyperfiltration after protein ingestion, during glucagon infusion, and in insulin-dependent diabetes is induced by a liver hormone: deficient production of this hormone in hepatic failure causes hepatorenal syndrome. Lancet. 1:195-197.

19. Lang, F., D. Häussinger, E. Tschernko, G. Capasso, and N.G. DeSanto. 1992. Proteins, the liver and the kidney. Hepatic regulation of renal function. Nephron. 61:1-4.

20. Woods, L.L. 1993. Mechanisms of renal hemodynamic regulation in response to protein feeding. Kidney Int. 44:659-675.

21. Castellino, P., R. Levin, J. Shohat, and R. DeFronzo. 1990. Effect of specific amino acid groups on renal hemodynamics in humans. Am. J. Physiol. 258(Renal Fluid Electrolyte Physiol. 27):F992-F997.

22. Claris-Appiani, A., B.M. Assael, A.S. Tirelli, G. Marra, and G. Cavanna. 1988. Lack of glomerular hemodynamic stimulation after infusion of branched-chain amino acids. Kidney Int. 33:91-94.

23. Lee, K.E., and R.A. Summerill. 1982. Glomerular filtration rate following administration of individual amino acids in conscious dogs. Quart. J. Exp. Physiol. 67:459-465.

24. Exton, J.H. S.B. Lewis, R.J. Ho, G.A. Robison, and C.R. Park. 1971 The role of cyclic AMP in the interaction of glucagon and insulin in the control of liver metabolism. Ann. NY Acad. Sci. 185:85-100.

25. Broadus, A.E., R.C. Northcutt, J.G. Hardman, E.W. Sutherland, and G.W. Liddle. 1970. Effects of glucagon on adenosine $3^{\prime}-5^{\prime}$-monophosphate and guanosine $3^{\prime}-5^{\prime}-$ monophosphate in human plasma and urine. J. Clin. Invest. 49: $2237-2245$.

26. Sovik, O., E. Heiervang, L. Aksnes, and S. Selvig. 1981. Responses of plasma adenosine 3 ',5'-monophosphate, blood glucose and plasma insulin to glucagon in humans. Scand. J. Clin. Lab. Invest. 41:669-674.

27. Strange, R.C., and O.D. Mjos. 1975. The sources of plasma cyclic AMP: studies in the rat using isoprenaline, nicotinic acid and glucagon. Eur. J. Clin. Invest. 5:147-152.

28. Hendy, G.N., S. Tomlinson, and J.L.H. O'Riordan. 1977. Impaired responsiveness to the effect of glucagon on plasma adenosine $3^{\prime}: 5^{\prime}$-cyclic monophosphate in normal man. Eur. J. Clin. Invest. 7:155-160.

29. Coulson, R., and R.H. Bowman. 1974. Excretion and degradation of exogenous adenosine $3^{\prime}, 5^{\prime}$-monophosphate by isolated perfused rat kidney. Life Sci. 14:545-556.

30. Butlen, D., and S. Jard. 1972. Renal handling of 3'-5'-cyclic AMP in the rat. The possible role of luminal $3^{\prime}-5^{\prime}$-cyclic AMP in the tubular reabsorption of phosphate. Pflügers Arch. 331:172-190.

31. Lorentz, W.B. 1974. The effect of cyclic AMP and dibutyryl cyclic AMP on the permeability characteristics of the renal tubule. J. Clin. Invest. 53:12501257.

32. Kuntziger, H., C. Amiel, N. Roinel, and F. Morel. 1974. Effects of parathyroidectomy and cyclic AMP on renal transport of phosphate, calcium and magnesium. Am. J. Physiol. 227:905-911.

33. Friedlander, G., S. Couette, C. Coureau, and C. Amiel. 1992. Mechanisms whereby extracellular adenosine $3^{\prime}, 5^{\prime}$-monophosphate inhibits phosphate transport in cultured opossum kidney cells and in rat kidney. J. Clin. Invest. 90:848-858.

34. Führ, J., J. Kaczmarczyk, and C.D. Krüttgen. 1955. Eine einfache colorimetrische Methode zur Inulinbestimmung für Nieren-Clearance-Untersu- 
chungen bei Stoffwechselgesunden und Diabetikern. Klin. Wochenschr. 33:729730 .

34a. Bankir, L., H. Martin, M. Ahloulay, and M. Déchaux. 1996. Circulating cAMP is probably an essential hepatorenal link influencing natriuresis. J. Hepatol. 25(Suppl. 1):98a. (Abstr.)

35. Friedlander, G., and C. Amiel. 1995. Extracellular nucleotides as modulators of renal tubular transport. Kidney Int. 47:1500-1506.

36. Podevin, R.A., and E.F. Boumendil-Podevin. 1975. Inhibition by cyclic AMP and dibutyryl cyclic AMP of transport of organic acids in kidney cortex. Biochim. Biophys. Acta. 375:106-114.

37. Podevin, R.A., E.F. Boumendil-Podevin, J. Bujoli-Roche, and C. Priol. 1980. Effects of probenecid on transport and metabolism of cyclic AMP by isolated rabbit renal tubules. Biochim. Biophys. Acta. 629:135-142.

38. Strewler, G.J. 1984. Release of cAMP from a renal epithelial cell line. Am. J. Physiol. 246(Cell Physiol. 15):C224-C230.

39. Grantham, J.J., and A.M. Chonko. 1991. Renal handling of organic anions and cations; excretion of uric acid. In The Kidney. B.M. Brenner and F.C. Rector, editors. W.B. Saunders, Philadelphia. 483-509.

40. Coulson, R., R.H. Bowman, and F. Roch-Ramel. 1974. The effects of nephrectomy and probenecid on in vivo clearance of adenosine $3^{\prime}, 5^{\prime}$-monophosphate from rat plasma. Life Sci. 15:877-886.

41. Zenser, T.V., and B.B. Davis. 1976. Mechanism of inhibition of organic acid transport in rabbit renal cortex by cyclic AMP. Metab. Clin. Exp. 25:11371142.

42. Morel, F., and A. Doucet. 1986. Hormonal control of kidney functions at the cell level. Physiol. Rev. 66:377-468.

43. Boumendil-Podevin, E.F., and R.A. Podevin. 1977. Transport and metabolism of adenosine $3^{\prime}: 5^{\prime}$-monophosphate and $\mathrm{N}^{6}, \mathrm{O}^{2 \prime}$-dibutyryl adenosine $3^{\prime}$ : $5^{\prime}$-monophosphate by isolated renal tubules. J. Biol. Chem. 252:6675-6681.

44. O'Brien, J.A., and R.C. Strange. 1975. The release of adenosine 3':5'cyclic monophosphate from the isolated perfused rat heart. Biochem. J. 152: $429-432$

45. Bitensky, M.W., V. Russell, and W. Robertson. 1968. Evidence for separate epinephrine and glucagon responsive adenyl cyclase systems in rat liver. Biochem. Biophys. Res. Commun. 5:706-710.

46. Park, C.R., S.B. Lewis, and J.H. Exton. 1972. Relationship of some hepatic actions of insulin to the intracellular level of cyclic adenylate. Diabetes. 21(Suppl. 2):439-446.

47. Bailly, C., and C. Amiel. 1982. Effect of glucagon on magnesium renal reabsorption in the rat. Pflügers Arch. 392:360-365.

48. Levy, M., and N.L. Starr. 1972. The mechanism of glucagon-induced natriuresis in dogs. Kidney Int. 2:76-84

49. O'Brian, J.T., C.D. Saudek, R.F. Spark, and R.A. Arky. 1974. Glucagon induced refractoriness to exogenous mineralocorticoid. J. Clin. Endocrinol. \& Metab. 38:1147-1149.

50. Pullman, T.N., A.R. Lavender, and I. Aho. 1967. Direct effects of glucagon on renal hemodynamics and excretion of inorganic ions. Metab. Clin. Exp. 16:358-373.

51. Staub, A., V. Springs, F. Stoll, and H. Elrick. 1957. A renal action of glucagon. Proc. Soc. Exp. Biol. Med. 94:57-60.

52. Rouffignac-de, C., J.M. Elalouf, and N. Roinel. 1991. Glucagon inhibits water and $\mathrm{NaCl}$ transports in the proximal convoluted tubule of the rat kidney. Pflügers Arch. 419:472-477.

53. Butlen, D., and F. Morel. 1985. Glucagon receptors along the nephron: ( $\left.{ }^{125} \mathrm{I}\right)$ glucagon binding in rat tubules. Pflügers Arch. 404:348-353.
54. Bailly, C., M. Imbert-Teboul, D. Chabardès, A. Hus-Citharel, M. Montégut, A. Clique, and F. Morel. 1980. The distal nephron of rat kidney: a target site for glucagon. Proc. Natl. Acad. Sci. USA. 77:3422-3424.

55. Parrilla, R., M.N. Goodman, and C.J. Toews. 1974. Effect of glucagon: insulin ratios on hepatic metabolism. Diabetes. 23:725-731.

56. Seitz, H.J., M.J. Müller, and P. Nordmeyer. 1976. Concentration of cyclic AMP in rat liver as a function of the insulin/glucagon ratio in blood under standardized physiological conditions. Endocrinology. 99:1313-1318.

57. Exton, J.H., S.B. Lewis, R.J. Ho, and C.R. Park. 1972. The role of cyclic AMP in the control of hepatic glucose production by glucagon and insulin. $A d v$. Cyclic Nucleotide Res. 1:91-101.

58. Angielski, S., M. Redlak, and M. Szczepanska-Konkel. 1990. Intrarenal adenosine prevents hyperfiltration induced by atrial natriuretic factor. Miner. Electrolyte Metab. 16:57-60.

59. Nammour, T.M., P.E. Williams, K.F. Badr, N.N. Abumrad, and H.R. Jacobson. 1991. The amino acid-induced alteration in renal hemodynamics is glucagon independent. J. Am. Soc. Nephrol. 2:164-171.

60. Elalouf, J.M., N. Roinel, and C. deRouffignac. 1986. Effects of glucagon and PTH on the loop of Henle of rat juxtamedullary nephrons. Kidney Int. 29: 807-813.

61. DiStefano, A., M. Wittner, R. Nitschke, R. Braitsch, R. Greger, C. Bailly, C. Amiel, J.M. Elalouf, N. Roinel, and C. deRouffignac. 1989. Effects of glucagon on $\mathrm{Na}^{+}, \mathrm{Cl}^{-}, \mathrm{K}^{+}, \mathrm{Mg}^{++}$and $\mathrm{Ca}^{++}$transports in cortical and medullary thick ascending limbs of mouse kidney. Pflügers Arch. 414:640-646.

62. Seney, F.D. 1987. Tubuloglomerular feedback regulation of GFR during infusion of glucagon. Xth Int. Cong. Nephrol., London, 561. (Abstr.)

63. Woods, L.L., B.E. Smith, and D.R. DeYoung. 1993. Regulation of renal hemodynamics after protein feeding: effects of proximal and distal diuretics. Am. J. Physiol. 264(Reg. Integr. Comp. Physiol. 33):R337-R344.

64. Woods, L.L., D.R. DeYoung, and B.E. Smith. 1991. Regulation of renal hemodynamics after protein feeding: effects of loop diuretics. Am. J. Physiol. 261(Renal Fluid Electrolyte Physiol. 30):F815-F823.

65. Gupta, A.K., R.V. Clark, and K.A. Kirchner. 1992. Effects of insulin on renal sodium excretion. Hypertension (Dallas). 19[Suppl. I]:78-82.

66. Torùn, B., and F. Chew. 1994. Protein-energy malnutrition. In Modern Nutrition in Health and Disease. M.E. Shils, J.A. Olson, and M. Shike, editors Lea \& Febiger, Malvern, PA.

67. Spark, R.F., R.A. Arky, P.R. Boulter, C.D. Saudek, and J.T. O'Brian. 1975. Renin, aldosterone and glucagon in the natriuresis of fasting. $N$. Engl. J. Med. 292:1335-1340.

68. Levy, M. 1978. Inability of glucagon to increase glomerular filtration rate in dogs with experimental cirrhosis and ascites. Can. J. Physiol. Pharmacol. 56:511-514.

69. Hoogenberg, K., R.P.F. Dullaart, N.J.M. Freling, S. Meijer, and W.J. Sluiter. 1993. Contributory roles of circulatory glucagon and growth hormone to increased renal hemodynamics in type 1 (insulin-dependent) diabetes mellitus. Scand. J. Clin. Lab. Invest. 53:821-828.

70. Unger, R.H., and L. Orci. 1975. The essential role of glucagon in the pathogenesis of diabetes mellitus. Lancet. 4:14-16.

71. Liljenquist, J.E., J.D. Bomboy, S.B. Lewis, B.C. Sinclair-Smith, P.W. Felts, W.W. Lacy, O.B. Crofford, and G.W. Liddle. 1974. Effect of glucagon on net splanchnic cyclic AMP production in normal and diabetic men. J. Clin. Invest. 53:198-204.

72. Ahloulay, M., and L. Bankir. 1996. Glucagon antibody infusion reduces GFR in diabetic rats. J. Am. Soc. Nephrol. 7:1868a. (Abstr.) 